Check for updates

Cite this: Phys. Chem. Chem. Phys., 2017, 19, 20930

Received 8th May 2017, Accepted 13th July 2017

DOI: $10.1039 / c 7 c p 03043 f$

rsc.li/pccp

\section{CO diffusion as a re-orientation mechanism in the $\mathrm{NaY}$ zeolite $\dagger$}

\author{
A. A. Rybakov, (D) a A. V. Larin (D)*a and D. P. Vercauteren ${ }^{*}$
}

\begin{abstract}
Our work is devoted to DFT calculations of the relative rotational and diffusional barriers for CO motions in zeolite $\mathrm{NaY}$. The diffusion jump of $\mathrm{CO}$ adsorbed in $\mathrm{NaY}$ from $\mathrm{Nall}$ to $\mathrm{Na}$ 'll has been confirmed as the favored way for $\mathrm{CO}$ re-coordination via either the $\mathrm{C}$ or the $\mathrm{O}$ atom to the $\mathrm{Na}$ cations instead of the $\mathrm{CO}$ rotation, hence explaining the mechanism which is responsible for the $\mathrm{CO}$ exchange between different positions and the changes in the intensities of the vibrational IR spectra. The fine structure of the vibrational $\mathrm{C}-\mathrm{O}$ bands is explained by the different $\mathrm{CO}$ locations of adsorbed mono- and dicarbonyl species. The calculated activation energy of intra-cage $\mathrm{CO}$ diffusion from Nall-CO to $\mathrm{Na}$ 'll-OC matches the respective experimental barrier observed in the $\mathrm{NaX}$ zeolite.
\end{abstract}

\section{Introduction}

Gas separation in zeolites and MOF structures is expected to be one of their main future applications. Verification of their effectiveness in separation requires the estimation of the diffusion coefficients in the intra- and intercrystalline pores for each candidate material. So far, various intra- or intercrystalline diffusion regions have been related to the domination of different molecular properties such as size or weight, respectively. ${ }^{1}$ To avoid any influence of intercrystalline diffusion on the measurements, sealing techniques for the intercrystalline pores using silica precursor deposition after CVD-treatment were applied for $\mathrm{DDR}^{1}$ and $\mathrm{MFI}^{2}$ zeolites. For intracrystalline $\mathrm{CO}$ diffusion, activation energies of $15.5 \mathrm{~kJ} \mathrm{~mol}^{-1}$ in $\mathrm{DDR}^{1}$ and $17.1 \mathrm{~kJ} \mathrm{~mol}^{-1}$ in $\mathrm{NaX}^{3}$ were, for example, obtained. Within the scope of the translational diffusion model, ${ }^{4}$ activation barriers were also reported in terms of the ratio between kinetic diameters and pore sizes. ${ }^{1}$ Nevertheless, comparison between $\mathrm{CO}$ and $\mathrm{CO}_{2}$ is difficult for such classification because of the estimated higher kinetic diameter of CO versus $\mathrm{CO}_{2}$ (3.76 ̊ for CO versus $3.30 \AA$ for $\mathrm{CO}_{2}{ }^{1}$ ) due to the evident opposite ratio of

\footnotetext{
${ }^{a}$ Chemistry Department, Moscow State University, Leninskie Gory, Moscow, GSP-2, 119991, Russia. E-mail: Nasgo@yandex.ru

${ }^{b}$ University of Namur, Rue de Bruxelles 61, Namur, B-5000, Belgium. E-mail: daniel.vercauteren@unamur.be

$\dagger$ Electronic supplementary information (ESI) available: Detailed discussion of the NaY model containing NaIII cations (Section S1), Table S1 with calculated CO molecular parameters, Table S2 being an analogue of Table 2 for the tentative NaY model containing NaIII cations with additional geometric characterization of adsorbed CO over NaIII (Table S3), and an animation avi-file of CO diffusion between NaII sites in neighbor supercages without CO rotation (case " $e$ " in Table 3). See DOI: $10.1039 / \mathrm{c} 7 \mathrm{cp} 03043 \mathrm{f}$
}

their molecular spatial parameters. $\$$ Theoretical computations of the activation energies required for the migration between the sites ${ }^{5,6}$ are rare and most of the data relative to diffusion were obtained experimentally. Hence, a deeper understanding of the relation between the diffusion behavior and molecular properties for $\mathrm{CO}$ in zeolites is desirable. The respective jump models over the sites of the NaY zeolite considered as an Ising lattice were already developed even for heavier benzene species. ${ }^{5}$

Another important field wherein the relation between molecular translations and rotations is extremely important is catalysis in zeolites and other solids. As recent theoretical studies, let us cite $\mathrm{CO}$ oxidation in the MgPHI zeolite, ${ }^{7} \mathrm{CO}_{2}$ hydrolysis in the $\mathrm{NaX}$ zeolite, ${ }^{8}$ or $\mathrm{CH}_{3} \mathrm{OH}$ reaction with $\mathrm{CuCO}_{3} \mathrm{Cu}$ carbonate species in the CuMOR zeolite. ${ }^{9}$ In all cases, the orientation of the reagents $\left(\mathrm{CO},{ }^{7} \mathrm{CO}_{2}, \mathrm{H}_{2} \mathrm{O},{ }^{8} \mathrm{CH}_{3} \mathrm{OH}^{9}\right)$ is determined by the media in the pores that can hardly be simulated at the cluster level. The knowledge of all allowed motions for the reagents with definite molecular properties (van der Waals radii, multipole moments, etc.) in a specific zeolite geometry under imposed conditions might be the decisive tip to predict the best position of the reactive center in the zeolite pores. In particular, the case of appropriate $\mathrm{CO}$ orientation and subsequent chemisorption in a periodic MgPHI model allowed a significant reduction in the CO oxidation barrier. ${ }^{7}$ Any new data on the restrictions of the CO motions will allow more accurate modeling of the CO dynamics in catalyzed reaction systems and will drastically reduce the number of candidate routes for time consuming modeling of reaction pathways.

Additional landmarks for CO diffusion can be found throughout a large number of IR studies of CO adsorption over

$\ddagger$ See footnote in Section 3.2. 
alkali and earth alkaline form zeolites. ${ }^{3,10-15}$ Two main peaks are most often assigned to MeII-CO and MeII-OC orientations, with Me being the alkali or earth alkaline cation, and alternative interpretations appeared as a consequence of a cationic rearrangement. For NaY, Grey et al. ${ }^{16,17}$ and Mellot-Draznieks et al. ${ }^{18}$ observed, using XRD data, a decrease of NaI' occupation and a formation of sites similar to the NaIII' site in NaX in the presence of adsorbed $\mathrm{C}_{2} \mathrm{~F}_{4} \mathrm{H}_{2}{ }^{16,17}$ or $\mathrm{CFCl}_{3}{ }^{18}$ species. Plant et al. admitted such a possibility of $\mathrm{NaI}^{\prime}$ migration to the NaIII' site upon the influence of $\mathrm{CO}_{2}$ to model the cationic diffusion. ${ }^{19}$ An analogous influence of $\mathrm{CO}$ on the cationic positions in $\mathrm{NaY}$ and CuNaY later led to assigning the origin of the peaks to NaII-OC-NaIII and NaII-CO-NaIII sites ${ }^{20}$ even if the experimental data did not confirm the possibility of CO diffusion and interaction with $\mathrm{NaI}^{\prime}$ in sodalite units of $\mathrm{NaY}^{10}{ }^{10}$ One should note that analogous dual cationic sites for $\mathrm{Me}^{+}-\mathrm{CO}-\mathrm{Me}^{+}$were already confirmed in MeZSM- $5^{21}$ and MeFER, ${ }^{22} \mathrm{Me}=\mathrm{Na}^{21,23}$ or $\mathrm{K},{ }^{21,22}$ zeolites, on the basis of combined DFT modeling and IR experiments to interpret the intermediate bands observed between the monocarbonyl peaks related to either Me-CO or Me-OC orientations. If the NaIII or NaIII' positions are occupied in NaY, then the NaII-OC (or CO)-NaIII (or NaIII') dual $\operatorname{sites}^{20}$ should lead to similar intermediate peaks in NaY. Recently, we have modeled the migration of alkali cations between crystallographic positions in MeRHO ( $\mathrm{Me}=\mathrm{Li}, \mathrm{Na}, \mathrm{K}, \mathrm{Cs})^{24}$ and $\mathrm{MeY}$ $(\mathrm{Me}=\mathrm{K}, \mathrm{Cs})^{25}$ upon formation of carbonate or hydrocarbonate anions whose interactions with cations have to be much more effective than the ones of $\mathrm{CO}$ and lead to cationic drift. Usually smaller CO interaction energies with cations stimulated us to verify the model of NaIII formation in $\mathrm{NaY}^{20}$ which should have direct consequences for the assignment of IR spectra.

The heats of the respective $\mathrm{CO} / \mathrm{OC}$ exchanges were determined using van't Hoff dependences of the IR intensities, ${ }^{13,14,26}$ but, to our best knowledge, no mechanism of CO redistribution with temperature was proposed. Such a redistribution has been shown to take place for $\mathrm{CO}$ adsorbed in $\mathrm{H}$ - and any cationic form zeolites. ${ }^{15}$ At first glance, the evident idea of CO rotation might resolve the problem of the respective mechanisms. Some attempts to assign the fine structure of $\mathrm{CO}$ vibrational peaks in IR spectra in $\mathrm{NaA}^{27}$ and $\mathrm{NaY}^{28}$ to rotational transitions only (in contrast to $\mathrm{CaA}, \mathrm{NaX}$, and $\mathrm{CaX}$ where no separate peaks were found) were already undertaken many years ago but were not well evidenced. A modeling of the rotational structure of fundamental CO transition was undertaken by Förster et al. by analyzing possible barriers in $\mathrm{NaA}$ and $\mathrm{NaCaA}$ with a simplified model of a hindered rotator. ${ }^{29}$ However, the absence of band widening (due to rotational P- and R-branches) for CO/NaZSM-5 at higher temperatures (123-293 K) does not validate the possible $\mathrm{CO}$ rotation for all temperatures and for all zeolites because the intensity ratio of the $\mathrm{CO}$ vibrational transitions varies between the $\mathrm{Me}-\mathrm{CO} / \mathrm{Me}-\mathrm{OC}$ bands within a wide range of temperatures. ${ }^{30}$ The hindrance of rotation is connected with electrostatic field and/or field gradient variations in the zeolite cages. If these properties decrease from the cation location towards the center of the zeolite $\mathrm{Y}$ cage, then almost free CO rotation is allowed far from the cation

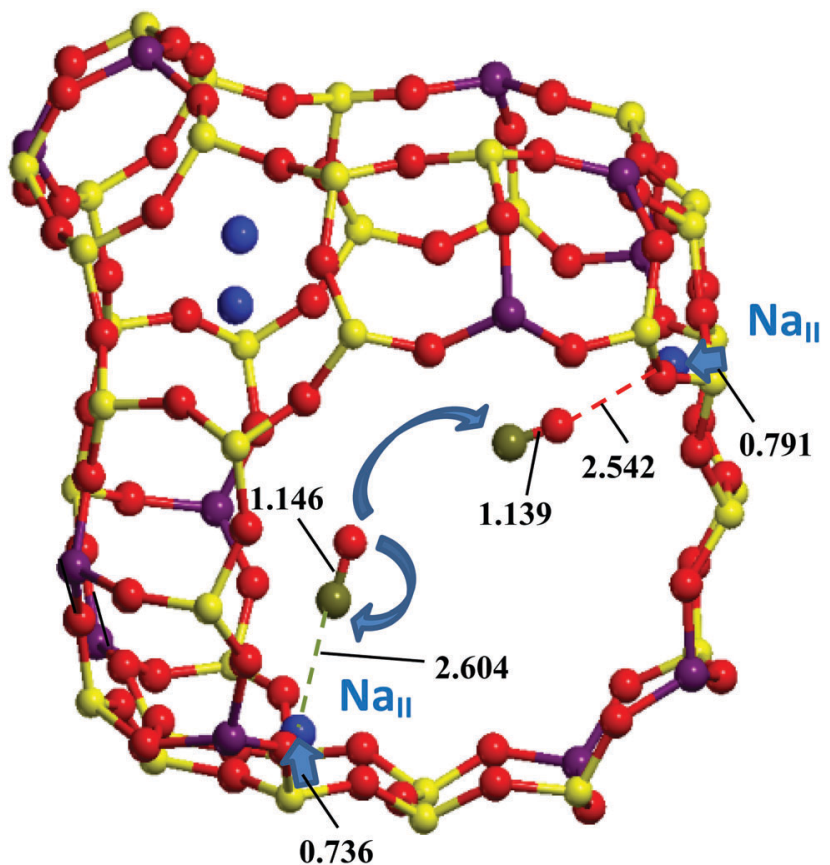

Fig. 1 Three-dimensional structure of a NaY cage and possible $\mathrm{CO}$ shift from one Nall to the other $\mathrm{Na}^{\prime} \mathrm{Il}$ site at the PBE/PAW level. The $|\mathrm{C}-\mathrm{O}|$ and $|\mathrm{C} / \mathrm{O}-\mathrm{Na}|$ distances (in $\AA$ ) are given. Curved arrows show translational and rotational CO motions. Linear arrows (non-scaled) illustrate the Nall displacements (in $\AA$ ) from the $6 \mathrm{R}$ planes passing through the three nearest $\mathrm{O}$ neighbors. $\mathrm{Na}, \mathrm{O}, \mathrm{Si}, \mathrm{Al}$, and $\mathrm{C}$ atoms are given in blue, red, yellow, magenta, and olive color, respectively.

in monovalent $\mathrm{Y}$ forms. The hypothesis that the $\mathrm{CO}$ and $\mathrm{OC}$ forms can be connected via a diffusion jump between two different Me cations hence deserves attention. As seen from Fig. 1, the CO shift from $\mathrm{NaII}-\mathrm{CO}$ to $\mathrm{Na}^{\prime} \mathrm{II}-\mathrm{OC}$ does not require any essential $\mathrm{CO}$ axis rotation due to the tetrahedral symmetry of the FAU supercage. Because of the larger electrostatic field and/or field gradient in divalent zeolite forms, this hindrance may be supposed for $\mathrm{CO}$ rotation in divalent forms as well and also explain the absence of rotational branches in the vibrational bands of $\mathrm{CO}$ adsorbed in zeolites.

Computations of CO adsorption over zeolite clusters showed the necessity of accurate estimation of electrostatic forces ${ }^{31}$ so that Density Functional Theory (DFT) (for example, with VASP $^{32,33}$ ) considering models with periodic boundary conditions (PBC) is needed. The computational scanning of the various Brønsted and Lewis sites in HMOR indeed demonstrated a variety of zeolite properties which can be obtained using a CO probe. ${ }^{34}$ Recently, various DFT functionals were compared for $\mathrm{CO}$ and $\mathrm{NO}$ adsorbed in transition metal form zeolites (CuCHA, CoCHA). ${ }^{35}$

The work presented here is devoted to the calculations of the rotational and diffusional barriers for CO motions in NaY. After the computational details (Section 2), we will discuss the results obtained with different DFT functionals regarding the geometries (Section 3.1), heats (Section 3.2), frequencies (Section 3.3), and barriers of $\mathrm{CO}$ rotation and of $\mathrm{NaII}-\mathrm{CO} / \mathrm{Na}^{\prime} \mathrm{II}-\mathrm{OC}$ diffusion (Section 3.4) relative to known experimental data. 


\section{Computational details}

Plane wave computations with $\mathrm{PBC}$ using the $\mathrm{PBE}^{36}$ and PBEsol $^{37}$ functionals within the projector augmented wave (PAW) method ${ }^{38,39}$ were performed with VASP. ${ }^{32,33}$ The energy cut-off was set to $500 \mathrm{eV}$. The Brillouin zone $k$-sampling was restricted to the $\Gamma$-point. Dispersion energy corrections were considered at the $\mathrm{D} 2{ }^{40}$ and $\mathrm{D} 3$ with Becke-Johnson damping (PBEsol-D3(BJ) $)^{41,42}$ levels.

Cell parameters were first optimized for the NaY model with the total formula $\mathrm{Na}_{12} \mathrm{Al}_{12} \mathrm{Si}_{36} \mathrm{O}_{96}$. These cell parameters were then used in all further calculations. Full geometry optimizations were performed for each structure (products, reagents) with the fixed cell parameters and switched off symmetry. The climbing image nudged-elastic band method (ciNEB) ${ }^{43,44}$ was used to determine the minimum energy path from reagents to products and to locate the transition state structure. Initial images of the intermediate configurations for the NEB calculations were built with the scripts provided by the Transition State Tools for VASP. We assumed that the convergence for geometry optimizations and NEB calculations was reached when the forces on each atom were below $0.05 \mathrm{eV} \AA^{-1}$.

$\mathrm{CO}$ vibrational frequencies were calculated using the finite difference method $(0.015 \AA$ atomic displacements) as implemented in VASP. Atoms of either one CO or two CO molecules, the closest (one or two) Na cations, and the zeolite $\mathrm{O}_{\mathrm{z}}$ atoms coordinated to the Na cations were allowed to move during the vibrational frequency calculations, while all other atoms were kept fixed. The error owing to fixation of the $\mathrm{O}_{\mathrm{z}}$ zeolite atoms was estimated to be $1 \mathrm{~cm}^{-1}$. For all reactions, the transition states showed a single imaginary frequency corresponding to the reaction path. Figures of the optimized models were made with MOLDRAW2.0. ${ }^{45}$ Videos of chemical reactions and normal mode animations were made using wxMacMolPlt. ${ }^{46}$

\section{Results}

\subsection{Geometry optimization}

The optimized cell volume of each considered NaY structure, including or not either one or two physisorbed $\mathrm{CO}$ molecules in various positions, varies most strongly with PBEsol-D3(BJ) $(1.71 \%)$ and optB86d $(0.64 \%)$, while minimal changes were obtained with PBE $\left(8 \times 10^{-3} \%\right)$ (Table 1 and Fig. 2). PBEsol led to an intermediate variation of $0.26 \%$. In all models, adsorption results in the NaII- $\mathrm{O}_{z}$ elongation, with $\mathrm{O}_{z}$ being the oxygen atom of the zeolite framework.

We also analyzed the consequence of Na shift from the NaII to NaIII site ${ }^{18-20}$ regarding the total energy (case 5 in Fig. 3), the IR spectra (Section 3.2), and the activation energy (Section S1, ESI $\dagger$ ). The cell volumes with NaIII cations are coherently lower by $-0.4,-0.3$, and $-0.8 \%$ with PBE, PBEsol, and optB86d, respectively, while the energies are less stable due to poor NaIII coordination by as much as 7.6, 6.1, and $5.8 \mathrm{kcal} \mathrm{mol}{ }^{-1}$, respectively (see Table 2 and Table S2, ESI $\dagger$ ). Let us also note that both DFT approaches with dispersion corrections we applied are less consistent relative to the volume perturbation
Table 1 Cell volume of $\mathrm{NaY}\left(\AA^{3}\right)$ and its variations $\Delta V(\%)$ due to $\mathrm{CO}$ species (excluding the case with Nalll) adsorbed at the $N$ sites of Nall type ( $N$ being the number of $\mathrm{Na}$ cations interacting with one or two $\mathrm{CO}$ molecules as noted in the first column) in the two different $\mathrm{Na}-\mathrm{CO}$ or $\mathrm{Na}-\mathrm{OC}$ orientations (distinguished by the order of $\mathrm{C}$ and $\mathrm{O}$ labels in the first column) calculated at the different DFT levels

\begin{tabular}{lccclc}
\hline Orientation & $N$ & PBE & PBEsol & PBEsol-D2 & OptB86d \\
\hline- & - & 3935.6 & 3889.3 & 3917.5 & 3910.2 \\
$\overline{-}^{a}$ & & 3920.7 & 3876.4 & - & 3880.3 \\
CO & 1 & 3935.5 & 3889.3 & 3858.4 & 3896.0 \\
OC & & 3935.3 & 3879.5 & 3849.3 & 3935.5 \\
2CO & & 3935.6 & $3888.7^{b}$ & 3848.2 & 3892.3 \\
CO, OC & & $3935.6^{c}$ & 3880.8 & 3847.6 & 3897.6 \\
2 CO & 2 & 3935.6 & 3889.1 & - & 3909.6 \\
$\Delta V$ & - & 0.008 & 0.26 & 1.79 & 0.64
\end{tabular}

${ }^{a}$ One NaII is replaced by NaIII. ${ }^{b}$ See the geometry in Fig. 2 b. ${ }^{c}$ See Fig. 2c.

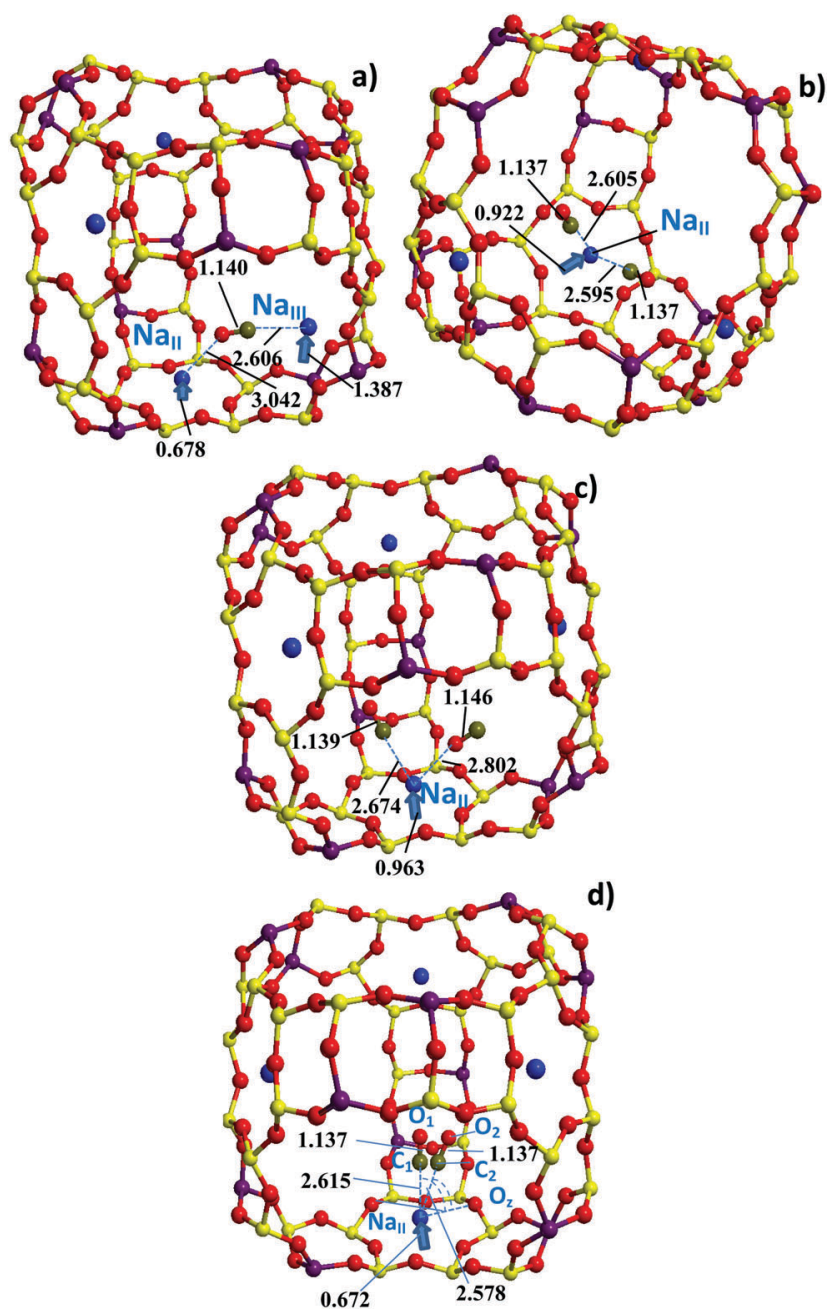

Fig. 2 Three-dimensional structure of a NaY cage with $\mathrm{CO}$ positions (a) between Nall and Nalll, or as (b) OC-Nall-CO or (c) CO-Nall-CO, and (d) Nall-CO optimized at the PBE (a and c), PBEsol (b), and PBEsol-D2 (d) levels. Dashed lines depict the $|\mathrm{C}-\mathrm{O}|$ and $|\mathrm{C} / \mathrm{O}-\mathrm{Na}|$ distances (in $\AA$ ) given (a) in Table S2 (ESI $\dagger$ ) and (b, $\mathrm{c}$ and d) in Table 2. Two degenerate CO positions are shown in (d). The atom color code is the same as in Fig. 1. Linear arrows (non-scaled) illustrate the Nall and Nalll displacements (in $\AA$ ) from the $6 R$ and $4 R$ planes, respectively, passing through the three nearest $O$ neighbors. 
due to CO adsorption. The variations of the volumes while adding either one or two CO molecules do not reveal a systematic trend (Table 1). For example, the cell optimization with one CO molecule for the NaII-CO or NaII-OC configurations led to opposite volume changes by -0.25 or $1.1 \%$ with PBEsol and optB86d, respectively. These large distortions look overestimated, while the minor change in the cell volume with one physisorbed molecule is more realistic with $\mathrm{PBE}$, i.e., less than $0.008 \%$ in Table 1.

The local NaII cationic geometry was then analyzed upon $\mathrm{CO}$ adsorption (Table 2). Three coinciding NaII- $\mathrm{O}_{\mathrm{z}}$ distances of $2.360 \AA$ (Table 2) were obtained at the PBE/PAW level in the $6 \mathrm{R}$

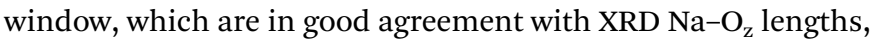
i.e., $2.337 \AA$ in $\mathrm{NaY}^{16,17}$ or NaNAT, ${ }^{47}$ i.e., as from 2.371 and $2.394 \AA$ towards the $\mathrm{O}_{\mathrm{w}}$ atoms of the nearest water molecules to $2.367,2.395,2.518$, and $2.615 \AA$ towards the zeolite $\mathrm{O}_{\mathrm{z}}$ atoms of NaNAT. ${ }^{47}$ The NaII coordination varies between usually lower coordinated NaIII' cations in the $4 \mathrm{R}$ window (with $\mathrm{NaIII}^{\prime}-\mathrm{O}_{\mathrm{z}}$ of $2.441,2.464,2.519,2.776 \AA$ ) and NaII in the similar FAU cage, i.e., $\left|\mathrm{NaII}-\mathrm{O}_{\mathrm{z}}\right|=2.311,2.316$, and $2.356 \AA$ at the PBE level. We remind that the NaY model with NaIII' was used herein as proposed in ref. 18-20 (more details in Section S1 of the ESI $\dagger$ ). The NaII- $\mathrm{O}_{\mathrm{z}}$ value of $2.360 \AA$ at the PBE level slightly shortens to 2.336 and 2.343 A with PBEsol and optB86d, respectively, also in reasonable agreement with the experimental data. ${ }^{16,47}$

The $\mathrm{Na}-\mathrm{O}_{z}$ distances elongate due to $\mathrm{CO}$ adsorbed at NaII (Table 2) in a less emphasized manner than those measured upon adsorption of 16 or $32 \mathrm{CF}_{3} \mathrm{CFH}_{2}$ molecules, ${ }^{16,17}$ i.e., from $2.337 \AA$ (no physisorbed molecules) to $2.478 \AA$ (16 molecules per unit cell or 2 molecules per NaY supercage) and $2.510 \AA$ (32 molecules per unit cell). ${ }^{16,17}$ Other $\mathrm{NaII}-\mathrm{O}_{\mathrm{z}}$ elongations were computed in the course of carbonate formation in the $\mathrm{NaX}$ zeolite. ${ }^{48}$ For comparison, the elongations of the shortest NaII- $\mathrm{O}_{\mathrm{z}}$ bonds due to one or two carbonate (or hydrocarbonate) species are given in Fig. 3 of ref. 48. One or two carbonates (or hydrocarbonates) per two NaX supercages are indeed closely connected to the NaII cation/cations, the average elongations being 0.07 and $0.08 \AA$ for one or two carbonates (or hydrocarbonates), respectively, within the most stable configurations and 0.19 and $0.16 \AA$ within the least stable configurations. ${ }^{48}$ These last calculated values are of the same order of value as the ones measured in NaY in the course of $\mathrm{CF}_{3} \mathrm{CFH}_{2}$ adsorption, $0.141 \AA$ (16 molecules or 2 molecules per supercage) and $0.173 \AA$ (32 molecules) from Table 4 of ref. 16 .

\subsection{Energy calculations}

The molecular properties of $\mathrm{CO}$ in the gas phase are required for comparison of the band shifts (BSs) and calculation of adsorption energies of $\mathrm{CO}$ in the zeolite framework. The total energies and molecular properties of $\mathrm{CO}$ in the gas phase calculated at different DFT levels are given in Table S1 (ESI $\dagger$ ). Among the three computational approaches, we note the slightly underestimated and overestimated heats of adsorption with PBE and PBEsol, respectively, relative to experiment ${ }^{10-12}$ at small coverage for $\mathrm{CO}$ (upper and lower boundaries given by dotted-dashed lines in Fig. 3; data are also presented in Table 3).

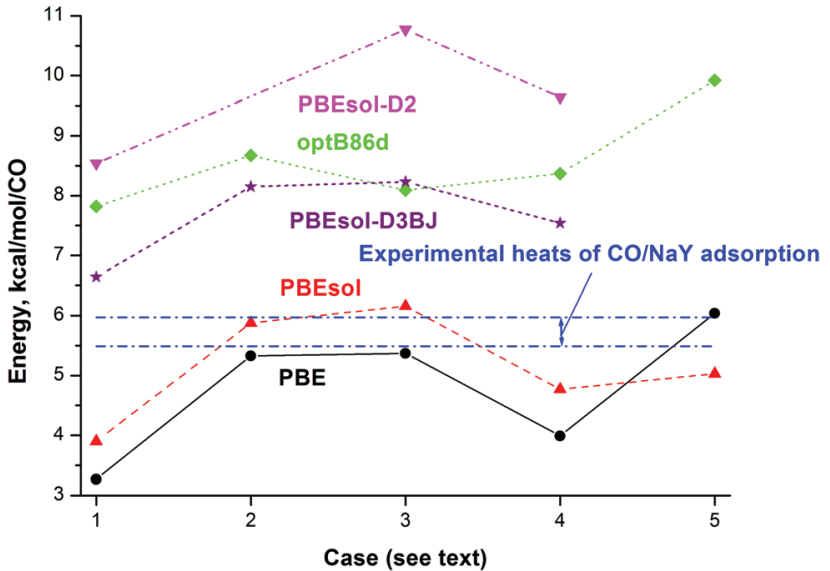

Fig. 3 Calculated total energy $\left(\mathrm{kcal} \mathrm{mol}^{-1}\right)$ per $\mathrm{CO}$ of each considered $\mathrm{NaY}$ model including the various configurations of $\mathrm{CO}$ species at the PBE (circles), PBEsol (triangles up), PBEsol-D2 (triangles down), PBEsol-D3BJ (stars), and optB86d (diamonds) levels and experimental heats of adsorption (upper and lower boundaries given via dotted-dashed lines ${ }^{10,11}$ ). Different cases correspond to adsorption of one $\mathrm{CO}$ (cases 3 and 5) or two CO (cases 1, 2, and 4) molecules at one Nall site (cases 1, 3, and 4), one Nalll site (case 5) or two Nall sites (case 2) coordinated via the $\mathrm{Na}-\mathrm{CO}$ orientation (cases 2 and 4) or $\mathrm{Na}-\mathrm{CO}$ plus $\mathrm{Na}-\mathrm{OC}$ orientations (case 1).

Values computed with optB86d, PBEsol-D2, and PBEsol-D3BJ are larger than the experimental heat values (to be compared with case 3 in Fig. 3).

Before discussing dicarbonyls, one has to consider the important example of monocarbonyls over NaII which is typical with all DFT methods used herein (Fig. 2d). Two CO molecules corresponding to different monocarbonyls with nearly the same energies of $-1156.92 \mathrm{eV}\left(\mathrm{C}_{1}-\mathrm{O}_{1}\right)$ and $-1156.92 \mathrm{eV}\left(\mathrm{C}_{2}-\mathrm{O}_{2}\right)$ at the PBEsol-D2 level (cases (e) in Table 2) were obtained, as shown in Fig. $2 \mathrm{~d}$. The $\mathrm{C}_{2}-\mathrm{O}_{2}$ molecule deviates by around $20^{\circ}$ from the $\mathrm{C}_{1}-\mathrm{O}_{1}$ axis orientation which is perpendicular towards the $6 \mathrm{R}$ plane, i.e., $\mathrm{O}_{\mathrm{z}}-\mathrm{Na}-\mathrm{C}_{2}=70.28^{\circ}$ versus $\mathrm{O}_{\mathrm{z}}-\mathrm{Na}-\mathrm{C}_{1}=90.25^{\circ}$. However, it does not lead to a valuable energy variation $\left(0.02 \mathrm{kcal} \mathrm{mol}^{-1}\right)$. The $\mathrm{C}_{1}-\mathrm{O}_{1} \rightarrow \mathrm{C}_{2}-\mathrm{O}_{2}$ motion between two nearly iso-energetic positions is also accompanied by a $\mathrm{Na}-\mathrm{C}$ shortening (0.037 $\mathrm{A})$ and a weak Na migration to a less symmetric position relative to the $\mathrm{O}_{\mathrm{z}}$ atoms of the $6 \mathrm{R}$ window. Comparing the $\mathrm{Na}-\mathrm{O}_{\mathrm{z}}$ distances at the PBEsol-D2 level with those calculated at the other levels (Table 2), one can guess that the $\mathrm{CO}$ position in monocarbonyls corresponds to the $\mathrm{C}_{1}-\mathrm{O}_{1}$ type (CO is nearly perpendicular to the $6 \mathrm{R}$ plane) with optB86d and to the $\mathrm{C}_{2}-\mathrm{O}_{2}$ type (tilt geometry) with PBE and PBEsol. In dicarbonyls, the $\mathrm{C}_{1}-\mathrm{Na}-\mathrm{C}_{2}$ angle is generally around $70^{\circ}$, i.e., 72.66, 72.44, and $71.83^{\circ}$ at the PBE, PBEsol, and optB86d levels, respectively. Hence each $\mathrm{CO}$ in dicarbonyls is far from the $\mathrm{Na}$ and is outside the abovementioned iso-energetic zone with a steric angle, formed by the $\mathrm{C}_{2}-\mathrm{O}_{2}$ deviation from the $\mathrm{C}_{1}-\mathrm{O}_{1}$ axis, around $40^{\circ}$. So, the different $\mathrm{CO}$ locations within this steric angle are characterized by the same energy (and slightly different BSs as shown below). An energy advantage of the $\mathrm{C}_{1}-\mathrm{O}_{1}$ or $\mathrm{C}_{2}-\mathrm{O}_{2}$ geometry can come from different $\mathrm{C}_{1}-\mathrm{O}_{1}$ and $\mathrm{C}_{2}-\mathrm{O}_{2}$ zero point energies (ZPEs). Our estimation at the PBEsol-D2 level leads to a 
Table 2 Total energy $U(\mathrm{eV})$, energy of adsorption $\Delta U\left(\mathrm{kcal} \mathrm{mol}^{-1}\right)$ per $\mathrm{CO}$ relative to the non-interacting NaY zeolite and gas phase CO (data in Table S1, ESI), molecular $|\mathrm{C}-\mathrm{O}|$ bond length and distances towards the $\mathrm{Na}$ and $\mathrm{O}_{\mathrm{z}}$ zeolite atoms ( $\left.\mathrm{A}\right), \mathrm{CO}$ frequencies $\left(\omega_{\mathrm{HF}}, \omega_{\mathrm{LF}}, \mathrm{cm}{ }^{-1}\right)$, and their shifts $\Delta \omega_{\mathrm{HF}}, \Delta \omega_{\mathrm{LF}}$ versus gas phase $\mathrm{CO}$ calculated at the different DFT levels. The CO orientation is given in column 2, the first atom of either $\mathrm{CO}$ or OC being directed towards Nall. $\mathrm{N}$ in the parentheses in column 2 is the number of $\mathrm{Na}$ cations interacting with one or two CO molecules if more than 2 molecules are adsorbed. For analogous models with Nalll cations, see Table S2 (ESI)

\begin{tabular}{|c|c|c|c|c|c|c|c|c|}
\hline DFT & Case $(N)$ & $-U$ & $-\Delta U$ & $|\mathrm{C}-\mathrm{O}|$ & $|\mathrm{C} / \mathrm{O}-\mathrm{Na}|^{a}$ & $\left|\mathrm{Na}-\mathrm{O}_{\mathrm{z}}\right|$ & $\omega_{\mathrm{HF}}, \omega_{\mathrm{LF}}$ & $\Delta \omega_{\mathrm{HF}}, \Delta \omega_{\mathrm{LF}}$ \\
\hline \multirow[t]{7}{*}{ PBE } & - & 1161.21 & - & - & - & $3 \times 2.360$ & - & - \\
\hline & $\mathrm{CO}$ & 1176.22 & 5.4 & 1.139 & 2.604 & $2.356,2.378,2.381$ & 2179.6 & 44.1 \\
\hline & OC & 1176.13 & 3.3 & 1.146 & 2.542 & $3 \times 2.378$ & 2112.8 & -22.7 \\
\hline & $\mathrm{CO}, \mathrm{CO}(2)$ & 1191.22 & 5.3 & $1.139,1.139$ & $2.618,2.617$ & $2.369,2.372,2.374,2.363,2.370,2.383$ & $2180.6,2178.3$ & $45.1,42.8$ \\
\hline & $\mathrm{CO}, \mathrm{OC}(1)^{b}$ & 1191.05 & 3.3 & $1.139,1.146$ & $2.674,2.802^{*}$ & $2.406,2.423,2.424$ & $2192.3,2122.3$ & $56.8,-13.2$ \\
\hline & $2 \mathrm{CO}(1)$ & 1191.11 & 4.0 & $1.140,1.140$ & $2.682,2.833^{*}$ & $2.415,2.440,2.446$ & $2172.8,2163.8$ & $37.3,28.3$ \\
\hline & $2 \mathrm{OC}(1)$ & 1190.96 & 0.3 & $1.146,1.146$ & $2.802^{*}, 2.766^{*}$ & $2.407,2.421,2.422$ & $2119.8,2113.9$ & $-15.7,-21.6$ \\
\hline \multirow[t]{6}{*}{ PBEsol } & - & 1129.31 & - & - & - & $3 \times 2.336$ & - & - \\
\hline & $\mathrm{CO}$ & 1144.13 & 6.2 & 1.137 & 2.569 & $2.333,2.353,2.355$ & 2192.6 & 39.3 \\
\hline & OC & 1144.04 & 4.1 & 1.145 & 2.523 & $2 \times 2.363,2.365$ & 2123.8 & -29.5 \\
\hline & $\mathrm{CO}, \mathrm{CO}(2)$ & 1158.92 & 5.9 & $1.137,1.137$ & $2.605,2.595$ & $2.344,2.348,2.358,2.350,2.353,2.355$ & 2193.4, 2189.5 & $40.1,36.2$ \\
\hline & $\mathrm{CO}, \mathrm{OC}(1)$ & 1158.75 & 3.9 & $1.138,1.145$ & $2.610,2.705^{*}$ & $2.370,2.391,2.394$ & $2191.8,2124.0$ & $38.5,-29.3$ \\
\hline & $2 \mathrm{CO}(1)^{c}$ & 1158.83 & 4.8 & $1.138,1.138$ & $2.625,2.761^{*}$ & $2.383,2.408,2.417$ & $2185.1,2175.4$ & $31.8,22.1$ \\
\hline \multirow[t]{7}{*}{ PBEsol-D2 } & - & 1144.90 & - & - & - & $3 \times 2.356$ & - & - \\
\hline & $\mathrm{CO}^{e}$ & 1159.92 & 10.8 & 1.137 & 2.578 & $2.324,2.345,2.348$ & 2196.2 & 42.9 \\
\hline & $\mathrm{CO}^{e}$ & 1159.92 & 10.8 & 1.137 & 2.615 & $2 \times 2.336,2.338$ & 2191.1 & 37.8 \\
\hline & OC & 1159.80 & 8.1 & 1.144 & 2.514 & $2.351,2.352,2.356$ & 2127.9 & -25.4 \\
\hline & $2 \mathrm{CO}(1)$ & 1174.84 & 9.6 & $1.139,1.138$ & $2.664,2.687$ & $2.391,2.401,2.405$ & $2185.9,2181.8$ & $32.6,28.5$ \\
\hline & $2 \mathrm{OC}(1)$ & 1174.63 & 7.2 & $1.144,1.144$ & $2.553,2.562$ & $2.391,2 \times 2.392$ & $2133.6,2130.6$ & $-19.7,-16.7$ \\
\hline & $\mathrm{CO}, \mathrm{OC}(1)$ & 1174.74 & 8.6 & $1.138,1.144$ & $2.655,2.584$ & $2.380,2.401,2.403$ & $2187.0,2131.7$ & $33.7,-21.6$ \\
\hline \multirow[t]{7}{*}{ PBEsol-D3(BJ) } & - & 1141.12 & - & - & - & $3 \times 2.343$ & - & - \\
\hline & $\mathrm{CO}$ & 1156.03 & 8.2 & 1.137 & 2.620 & $2.366,2.364,2.350$ & 2190.3 & 37.8 \\
\hline & $\mathrm{OC}$ & 1155.92 & 5.8 & 1.145 & $2.537^{*}$ & $2.360,2.360,2.367$ & 2124.6 & -27.9 \\
\hline & $\mathrm{CO}, \mathrm{CO}(2)$ & 1170.93 & 8.2 & $1.137,1.138$ & $2.638,2.637$ & $2.356,2.353,2.352,2.364,2.352,2.356$ & $2190.9,2186.4$ & $38.4,33.9$ \\
\hline & $\mathrm{CO}, \mathrm{OC}(1)^{b}$ & 1170.80 & 6.6 & $1.138,1.144$ & $2.691,2.861^{*}$ & $2.393,2.392,2.380$ & $2187.4,2128.2$ & $34.9,-24.3$ \\
\hline & $2 \mathrm{CO}(1)$ & 1170.87 & 7.5 & $1.138,1.139$ & $2.714,2.909$ & $2.391,2.410,2.405$ & $2180.3,2173.9$ & $27.8,21.4$ \\
\hline & $2 \mathrm{OC}(1)$ & 1170.68 & 5.4 & $1.145,1.144$ & $2.835^{*}, 2.757^{*}$ & $2.392,2.390,2.385$ & $2133.6,2127.0$ & $-18.9,-25.5$ \\
\hline \multirow[t]{8}{*}{ OptB86d } & - & 1056.95 & - & & - & $3 \times 2.343$ & - & - \\
\hline & $\mathrm{CO}$ & 1069.97 & 8.1 & 1.138 & 2.607 & $2.348,2.350,2.351$ & 2178.7 & 49.2 \\
\hline & OC & 1069.93 & 7.0 & 1.146 & 2.502 & $2 \times 2.362,2.364$ & 2111.3 & -18.2 \\
\hline & $\mathrm{CO}, \mathrm{CO}(2)$ & 1083.06 & 8.7 & $1.138,1.138$ & $2.604,2.608$ & $2.343,2.348,2.360,2.350,2.353,2.354$ & $2180.7,2175.8$ & $51.2,46.3$ \\
\hline & $\mathrm{CO}, \mathrm{OC}(1)$ & 1082.96 & 7.5 & $1.139,1.146$ & $2.640,2.951^{*}$ & $2.362,2.381,2.386$ & $2174.3,2109.3$ & $44.8,-20.5$ \\
\hline & $\mathrm{CO}, \mathrm{OC}(1)^{d}$ & 1083.00 & 8.0 & $1.139,1.146$ & $2.668,2.628^{*}$ & $2.369,2.387,2.388$ & $2173.8,2113.1$ & $44.3,-16.7$ \\
\hline & CO, OC (2) & 1082.99 & 7.8 & $1.138,1.145$ & $2.493^{*}, 2.602$ & $2.356,2.358,2.359,2.344,2.346,2.348$ & $2181.3,2115.0$ & $51.8,-14.5$ \\
\hline & $2 \mathrm{CO}(1)$ & 1083.03 & 8.4 & $1.139,1.140$ & $2.646,2.984$ & $2.364,2.404,2.407$ & $2171.7,2160.4$ & $42.2,30.9$ \\
\hline
\end{tabular}

${ }^{a}$ The case of an O-connected CO molecule in dicarbonyls at one NaII $(N=1$, Fig. $2 \mathrm{c})$ and relevant cases for two NaII $(N=2)$ are marked by stars. ${ }^{b}$ See Fig. 2c. ${ }^{c}$ See Fig. 2b. ${ }^{d}$ Starting geometry taken from the case with the total energy of $-1082.96 \mathrm{eV}$ to reach a more symmetric dicarbonyl structure with energy of -1083.00 eV. ${ }^{e}$ Case shown in Fig. $2 \mathrm{~d}$.

Table 3 Heat of $\mathrm{CO} / \mathrm{OC}$ re-orientation $\left(\Delta U, \mathrm{kcal} \mathrm{mol}^{-1}\right)$, activation barrier of $\mathrm{CO}$ rotation $\left(E_{\mathrm{rot}}^{\#}\right.$, $\left.\mathrm{kcal}_{\mathrm{mol}}^{-1}\right)$ and diffusion between $\mathrm{Nall}$ sites $\left(E_{\text {dif, }}^{\#}\right.$ $\mathrm{kcal} \mathrm{mol}{ }^{-1}$ ), isosteric heats of $C O$ adsorption $Q_{\mathrm{st}}=-\Delta U+R T$, where $R T$ was evaluated as the average value between 0.5 and $0.6 \mathrm{kcal}^{\mathrm{mol}}{ }^{-1}$ for the experimental conditions at $250-318 \mathrm{~K}$ in ref. $10, \Delta U$ values are from Table 2, splitting of the CO-OC frequencies $\left(\Delta \omega=\omega_{\mathrm{HF}}-\omega_{\mathrm{LF}}, \mathrm{cm}^{-1}\right)$, and imaginary frequencies $-\mathrm{i} \omega, \mathrm{cm}^{-1}$, at the transition states for $\mathrm{CO}$ rotation and diffusion in NaY calculated at the different DFT levels

\begin{tabular}{|c|c|c|c|c|}
\hline Parameter & PBE & PBEsol-D3(BJ) & OptB86d & Experiment \\
\hline$\Delta U$ & $2.0,0.7^{a}$ & $2.1,^{h} 1.3,,^{a, h} 2.7,^{i} 1.8$ & $1.1,0.02^{a}$ & $0.6^{10-12}$ \\
\hline$E_{\mathrm{rot}}^{\#}$ & 5.4 & 5.3 & - & - \\
\hline$-\mathrm{i} \omega_{\text {rot }}$ & 107.4 & 96.6 & - & - \\
\hline$E_{\mathrm{dif}}^{\#}$ & $4.1,5.3,^{b} 5.5,^{c} 0.7,^{d} 4.5,{ }^{e} 4.9^{f}$ & $4.7,6.0,^{b} 1.0,{ }^{d} 4.0,^{e} 4.6^{f}$ & - & $4.1^{g 3}$ \\
\hline$-\mathrm{i} \omega_{\mathrm{dif}}$ & $19.1,71.8,^{b} 98.5,^{c} 35.2,^{d} 72.6,^{e} 109.9^{f}$ & $73.7,71.5,^{b} 45.4,{ }^{d} 77.7,{ }^{e} 80.5^{f}$ & - & - \\
\hline & 5.9 & $6.7^{h} 11.3^{i}$ & 8.7 & $(5.5-6.1) \pm 0.5,^{10-12} 5.0,,^{28} 5.6^{g}$ \\
\hline$\Delta \omega$ & 66.8 & $65.7,68.8,^{h} 63.2-68.3^{i}$ & 67.4 & $53,{ }^{14} 49^{15}$ \\
\hline
\end{tabular}

${ }^{a}$ At one NaIII site. ${ }^{b} \mathrm{CO}$ rotation along the diffusion trajectory, and it is bonded with NaII with the $\mathrm{C}$ atom in the beginning and in the end of migration. ${ }^{c}$ Motion towards the already occupied NaII site. ${ }^{d}$ Migration from the NaII to NaIII site. ${ }^{e}$ Diffusion between NaII sites in neighbor supercages without CO rotation (see the animation file in the ESI). ${ }^{f}$ CO rotation along diffusion between NaII sites in neighbor supercages maintaining the NaII-CO orientation. ${ }^{g}$ For the NaX zeolite. ${ }^{3} h$ PBEsol. ${ }^{i}$ PBEsol-D2. 
minor value of $-0.03 \mathrm{kcal} \mathrm{mol}^{-1}\left(10 \mathrm{~cm}^{-1}\right)$ with a higher ZPE for the $\mathrm{C}_{1}-\mathrm{O}_{1}$ type. This $\mathrm{ZPE}$ estimate corresponds to 9 degrees of freedom for the Na-CO complex versus the other fixed zeolite atoms.

The addition of a second $\mathrm{CO}$ molecule at a neighbor NaII site as NaII-CO in the FAU cavity (case 2 in Fig. 3) leads to different energy changes per CO with the different DFT methods, i.e., it slightly decreases with PBE and PBEsol but increases with optB86d. The adsorption of a second CO molecule at the same NaII site as $\mathrm{Na}-\mathrm{CO}$ (case 4 in Fig. 3) or Na-OC (case 1 in Fig. 3) orientations decreases the energy per $\mathrm{CO}$ (in absolute values) in the same manner with both PBE and PBEsol. The average energy per CO changes very little with $\mathrm{CO}$ adsorption at the optB86d level, which thus clearly underestimates the role of CO-CO interactions. According to Egerton and Stone, the isosteric heat of $\mathrm{CO} / \mathrm{NaY}$ adsorption is nearly constant at small coverage, i.e., from $5 \times 10^{-8}$ to $10^{-7} \mathrm{~m}^{3} \mathrm{~g}^{-1}$. ${ }^{10}$ The $\mathrm{CO} / \mathrm{NaX}$ case is characterized by a quick decrease of the heat of adsorption with coverage ${ }^{49}$ while optB86d demonstrates a rather opposite trend. Based on the narrow interval of the CO coverage and the nearly constant heat of adsorption behavior known for $\mathrm{CO} / \mathrm{NaY},{ }^{10}$ it is difficult to finally conclude which heat dependence (increase, decrease, or minor dependence) on the CO coverage is closer to the reality. Let us add that the possible modifications of cationic sites at higher CO coverage and the appearance of NaIII sites also complicate the question.

Both PBE and optB86d lead to higher adsorption energies per CO when the NaIII site is occupied (case 5 in Fig. 3). If the less stable NaIII centers with higher adsorption energy are occupied at higher CO coverage, they will moderate the decrease of the adsorption heat with coverage or they will even change the trend to the opposite. The problem is then to determine the coverage at which high CO concentration leads to the migration of $\mathrm{CO}$ from $\mathrm{NaI}^{\prime}$ to NaIII' sites, but the problem is outside the current study as we focus on small coverage only. We thus compared the adsorption energy gain in the Henry domain (or close to it) at all three PBE, PBEsol, and optB86d levels due to the increase of the single CO interaction with the NaIII cation $\left(6.0,5.0\right.$, and $\left.9.9 \mathrm{kcal} \mathrm{mol}^{-1}\right)$ versus the NaII cation (5.4, 6.2, and $8.1 \mathrm{kcal} \mathrm{mol}^{-1}$ ) as their differences $0.7,-1.1, \S$ and $1.8 \mathrm{kcal} \mathrm{mol}^{-1}$, respectively. The values have to be compared to the destabilization of the NaY zeolite, i.e., the price to move one cation from the NaII to the NaIII site, 7.6, 6.1, and $5.8 \mathrm{kcal} \mathrm{mol}^{-1}$ at the PBE, PBEsol, and optB86d levels, values that cannot be compensated by the higher adsorption energies at the NaIII site instead of NaII, i.e., 0. 7, -1.1, and $1.8 \mathrm{kcal} \mathrm{mol}^{-1}$ at the PBE, PBEsol, and optB86d levels. So, the formation of NaIII cations in NaY cannot be justified thermodynamically if one uses one CO molecule per NaIII. If one would manually construct a NaY model with NaIII cations coming from the NaI positions where they are more tightly

$\S$ The negative value with PBEsol-D shows that CO interacts more strongly with NaII than with NaIII; therefore, no gain comes from the adsorption energy at the PBEsol level.

T The same estimation is valid for NaIII' according to ref. 20. connected by three shortest NaI-O distances of 2.251, 2.228, and $2.238 \AA$ instead of the shortest 2.360, 2.336, and $2.343 \AA$ for NaII-O at the PBE, PBEsol, and optB86d levels (Table 2), then the destabilization would be even larger. In relation to this, here we mention that additional restrictions on the formation of NaIII cations can be obtained from spectroscopic interpretations.

The NaII-OC and NaII-CO distance values illustrate the deviations between mono- and dicarbonyl species. When monocarbonyls are observed in the framework, the NaII-CO distance is generally shorter than NaII-OC. When dicarbonyls are formed, it is often the opposite. $\|$ In our opinion, this comes from the non-equivalent $\mathrm{CO}$ positions which cannot be achieved at the NaII site of nearly $C_{3}$ symmetry, maintaining minimal CO-CO repulsion. As a result, one of the CO molecules, which can be either O-connected, or C-connected, is closer to the $4 \mathrm{R}$ windows near NaII. The shift to the $4 \mathrm{R}$ oxygens suggests possible multiple minima near the zeolite walls mainly due to dispersion energy. The distances from CO to the $4 \mathrm{R} \mathrm{O}_{\mathrm{z}}$ are summarized in Table S3 (ESI $\dagger$ ). For example, we would like to pinpoint the CO-NaII-OC case (whose optB86d energy is $-1082.96 \mathrm{eV}$ in Table 2) with the remote OC location (2.951 $\AA$ ). At the same optB86d level, one $\mathrm{CO}$ is also remote from NaII by as much as $2.984 \AA$ (the "2CO” case whose energy is $-1083.03 \mathrm{eV}$ in Table 2). For CO-NaII-OC, we modified the initially optimized position for the O-connected $\mathrm{CO}$ and obtained a more stable symmetric geometry (whose optB86d energy is $-1083.00 \mathrm{eV}$ ), leading to an energy gain of $1.0 \mathrm{kcal} \mathrm{mol}^{-1}$. The $|\mathrm{O}-\mathrm{Na}|=2.668 \AA$ and $|\mathrm{O}-\mathrm{Na}|=$ $2.628 \AA$ distances were then shifted to the conventional ratio when $|\mathrm{C}-\mathrm{Na}|>|\mathrm{O}-\mathrm{Na}|$ as for single adsorbed CO species (Table 2). The corrected more symmetric geometries, however, do not lead to drastic changes for the $\omega_{\mathrm{HF}}$ and $\omega_{\mathrm{LF}}$ frequencies as shown in Section 3.3. The displacement towards the $4 \mathrm{R}$ window is less emphasized at the PBE level with underestimated dispersion energy, although differences of CO orientations in adsorbed monoand dicarbonyl species are evident (Table 2). Such a situation was already shown earlier for larger cations like in RbY only using a pair-wise addition scheme, ${ }^{50}$ but the various examples in the current work confirm the role of the NaY cell geometry to explain the differences in CO orientations in mono- and dicarbonyl species. The inequality of the positions of the two CO molecules in the CO-NaII-OC dicarbonyls is one of the reasons for the different $\mathrm{CO}$ frequencies without essential coupling between the vibrational CO-CO modes as will be discussed in the next part.

\subsection{Band shift calculations}

The CO vibration frequencies for species adsorbed at the one NaII $(N=1)$ or at two different NaII cations $(N=2)$ are given in Table 2. The DFT frequency splittings $\Delta \omega=\omega_{\mathrm{HF}}-\omega_{\mathrm{LF}}$

\| It is also important to address the question of the higher kinetic diameter of CO versus $\mathrm{CO}_{2}{ }^{1}$ The same PBE/PAW level of theory gives for $|\mathrm{Na}-\mathrm{OCO}|=2.300-2.316 \AA$ (Table S9 of SEM in ref. 25) that is slightly shorter than $|\mathrm{Na}-\mathrm{OC}|=2.542 \AA$ herein (Table 2). But together with two $|\mathrm{C}-\mathrm{O}|$ bond lengths of $1.178 \AA$ in $\mathrm{CO}_{2}$, the sum of the distances results in a higher $\mathrm{CO}_{2}$ diameter. 
Table $4 \mathrm{HF}$ and LF frequencies $\left(\omega_{\mathrm{HF}}, \omega_{\mathrm{LF}}, \mathrm{cm}^{-1}\right)$ and total splitting $\left(\Delta \omega=\omega_{\mathrm{HF}}-\omega_{\mathrm{LF}}, \mathrm{cm}^{-1}\right)$ over NaY calculated at the different DFT levels

\begin{tabular}{|c|c|c|c|c|c|c|c|c|}
\hline Type & PBE & PBEsol & PBEsol-D2 & PBEsol-D3(BJ) & OptB86d & $\mathrm{B} 3 \mathrm{LYP}^{c}$ & Pair-wise $^{d}$ & Exper. \\
\hline$\Delta \omega_{\mathrm{HF}}$ & 44.1 & 39.3 & $42.9,37.8$ & 37.8 & 49.2 & 30.0 & 30.0 & $32,^{51} 28^{15}$ \\
\hline$\Delta \omega_{\mathrm{LF}}$ & $-22.7,-7,^{a}-20^{b}$ & -29.5 & -25.4 & -27.9 & -18.2 & -19.0 & $-40.5^{e}$ & $-21^{15}$ \\
\hline$\Delta \omega$ & 66.8 & 68.8 & $68.3,63.2$ & 65.7 & 67.4 & 49.0 & 70.5 & $53,{ }^{14} 49^{15}$ \\
\hline
\end{tabular}

${ }^{a}$ PBE1 periodic model (48T) of NaY with the NaII-CO-NaIII location (Table 2 of ref. 20). ${ }^{b}$ PBE2 periodic model (48T) of NaY with the NaII-CO-NaIII location (Table 2 of ref. 20). ${ }^{c}$ Cluster model $(42 \mathrm{~T})$ of $\mathrm{NaY}$ with the $6-311++\mathrm{G}(\mathrm{d}, \mathrm{p})(\mathrm{Na}-\mathrm{CO}-\mathrm{Na}) / 6-31 \mathrm{G}(\mathrm{d})\left(\mathrm{Al}, \mathrm{Si}, \mathrm{O}_{\mathrm{z}}, \mathrm{Na}^{\prime}\right)$ basis set, with $\mathrm{Na}{ }^{\prime}$ being all cations except the two $\mathrm{Na}$ in close contact with CO; the case $\mathrm{CO}$ and OC correspond to NaII-CO-NaIII and NaII-OC-NaIII, respectively. ${ }^{20} d{ }^{d}$ Pair-wise addition scheme. ${ }^{50} e$ This overestimated absolute value comes from the problem of the approximated repulsive constant for the $\mathrm{CO}^{-} \mathrm{O}_{\mathrm{z}}$ orientation which has no minimum. ${ }^{50}$

between NaII-CO (high frequency or HF branch) and NaII-OC (low frequency or LF branch) are overestimated matching the experimental value of $66 \mathrm{~cm}^{-1}$ for NaZSM- $5^{30}$ (Table 4). Note that all these values should be compared with characteristic full-width at half-height (FWHH) values of the experimental CO bands and their intensity to evaluate the probability of their registration. The iso-energetic zone for the $\mathrm{CO}$ location in monocarbonyls (see Section 3.2) is described by different $\Delta \omega$ values at the PBEsol-D2 level (Tables 2 and 4), i.e., from $42.9 \mathrm{~cm}^{-1}\left(\mathrm{C}_{2}-\mathrm{O}_{2}\right.$ tilt type in Fig. $\left.2 \mathrm{~d}\right)$ to $37.8 \mathrm{~cm}^{-1}\left(\mathrm{C}_{1}-\mathrm{O}_{1}\right.$ type being nearly perpendicular to the $6 \mathrm{R}$ plane). The change from one position to the other $\left(\mathrm{C}_{1}-\mathrm{O}_{1}\right.$ to $\mathrm{C}_{2}-\mathrm{O}_{2}$ or inversely) upon varying the conditions is the reason for the parallel drift of the NaII-CO band peak. Such a small order of value $\left(4 \mathrm{~cm}^{-1}\right)$ for the NaII-CO BS from 2175 to $2171 \mathrm{~cm}^{-1}$ was already observed with pressure. ${ }^{51}$

One important issue for our computations is the discussion of the dicarbonyl models of two CO-NaII-CO and OC-NaII-CO types. We show below that the $\omega_{\mathrm{HF}}$ splitting between mono- and dicarbonyls in $\mathrm{NaY}$ is large enough to explain the experimental difference relative to the fine structure of the $\omega_{\mathrm{HF}}$ band in NaZSM-5. In NaY, the symmetric shoulders at $2183 \mathrm{~cm}^{-1}$ (red shifted $+12 \mathrm{~cm}^{-1}$ relative to the main band at $2171 \mathrm{~cm}^{-1}$ ) and $2156 \mathrm{~cm}^{-1}$ (blue shifted $-15 \mathrm{~cm}^{-1}$ ) are present within a wide temperature range,${ }^{15}$ while no such shoulders have been observed in NaZSM-5. ${ }^{15}$

First, the non-equivalence of $\mathrm{CO}$ modes in mono- and dicarbonyl species is not a consequence of vibrational $\mathrm{CO}-\mathrm{CO}$ coupling in dicarbonyls. A simple verification of their negligible impact can be done when the calculation of the frequencies is performed upon fixed coordinates of the neighbor $\mathrm{CO}$ of the same dicarbonyl species. For example, for the OC-NaII-CO dicarbonyl, the alternate freezing of the second CO leads to $\Delta \omega$ values of 2172.8 and $2163.1 \mathrm{~cm}^{-1}$ (from two separate frequency computations) instead of 2172.8 and $2163.8 \mathrm{~cm}^{-1}$ (from one single computation with mobile atoms of both $\mathrm{CO}$ molecules) at the PBE level (case "2CO (1)" in Table 2). The unique case of interacting $\mathrm{CO}-\mathrm{CO}$ molecules was obtained in the CO-NaII-OC dicarbonyl at the PBEsol-D2 level. ${ }^{* *}$ The respective Cartesian components of the vibrational vectors possess similar orders of values for both $\mathrm{C}$ and $\mathrm{O}$ atoms for both $\mathrm{CO}$

** In the case of the other DFT methods, the extent of coupling is weaker, i.e., at the PBE level only one component of the second CO presents comparable values, i.e., $y(\mathrm{C} 2)=-0.13, y(\mathrm{O} 2)=-0.10$, while the other $x$ - and $z$-components of the $\mathrm{C} 2$ and $\mathrm{O} 2$ atoms are much smaller. molecules, i.e., $x(\mathrm{C} 1)=-0.638, y(\mathrm{C} 1)=-0.269, z(\mathrm{C} 1)=0.016$, and $x(\mathrm{C} 2)=-0.162, y(\mathrm{C} 2)=0.249, z(\mathrm{C} 2)=0.006$. One should, however, emphasize that the existence of CO-NaII-OC dicarbonyl remains in question.

Second, only the PBE/PAW type of calculation allows an interpretation of the red shifted $2183 \mathrm{~cm}^{-1}$ branch $^{15}$ due to the $\Delta \omega_{\mathrm{HF}}$ increase in CO-NaII-CO dicarbonyl complexes up to $56.8 \mathrm{~cm}^{-1}\left(\omega_{\mathrm{HF}}=2192.3 \mathrm{~cm}^{-1}\right.$ in Table 2$)$. The blue shifted peak (relative to $2179.6 \mathrm{~cm}^{-1}$ for monocarbonyls in Table 2) originates from OC-NaII-CO, i.e., $\Delta \omega_{\mathrm{HF}}=37.3 \mathrm{~cm}^{-1}$ (or $\omega_{\mathrm{HF}}=$ $2172.8 \mathrm{~cm}^{-1}$ in Table 2). The $\omega_{\mathrm{HF}}$ splitting between two $\mathrm{CO}$ molecules at two neighbor NaII sites (case "CO, CO (2)") is smaller, varying between $2.3 \mathrm{~cm}^{-1}$ (PBE) and $4.9 \mathrm{~cm}^{-1}$ (optB86d) that might also be resolved experimentally (Table 2). The dicarbonyls are less energetically favored with all three DFT functionals (Table 2), thus explaining their lower intensities compared to the main peak. The adsorption energy differences for CO-NaII-CO and OC-NaII-CO are rather close, i.e., $2.1 \mathrm{kcal} \mathrm{mol}^{-1}(5.4-3.3=$ $2.1 \mathrm{kcal} \mathrm{mol}^{-1}$ from Table 2) and $1.4 \mathrm{kcal} \mathrm{mol}^{-1}(5.4-4.0=$ $1.4 \mathrm{kcal} \mathrm{mol}^{-1}$ from Table 2), respectively, relative to the NaII-CO adsorption energy (5.4 kcal $\mathrm{mol}^{-1}$ ) at the PBE level. Therefore, these branches will vary nearly simultaneously with the experimental conditions (pressure or temperature). The asymmetry of the main $\omega_{\mathrm{HF}}$ peak at any temperature in $\mathrm{NaY}$, i.e., shoulder or shoulders on the blue shifted side, does not contradict the calculated results because all DFT functionals confirm the additional blue shifted peaks relative to the main CO transition in NaII-CO. Concerning NaZSM-5, we unfortunately could not perform the necessary PBC computations using VASP due to its large cell dimensions. As a result, we can only suggest that the dicarbonyl complexes in NaZSM-5 can either be much less stable than in NaY, or present identical locations of both $\mathrm{CO}$ molecules, very close to the positions of the monocarbonyl due to the symmetry of the $\mathrm{Na}$ sites so that the branches nearly coincide and cannot be observed.

\subsection{Activation energies for $\mathrm{CO}$ diffusion and rotation}

The ciNEB algorithm ${ }^{43,44}$ was applied to find transition states (TSs) for both CO rotation at one NaII cation and CO migration between two NaII cations in either one or two neighbor FAU supercages. The closeness of both PBE (activation barrier of

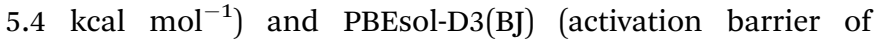
$5.3 \mathrm{kcal} \mathrm{mol}^{-1}$ ) energy profiles along the rotation trajectory (Fig. 4) shows the minor role of the dispersion energy terms 


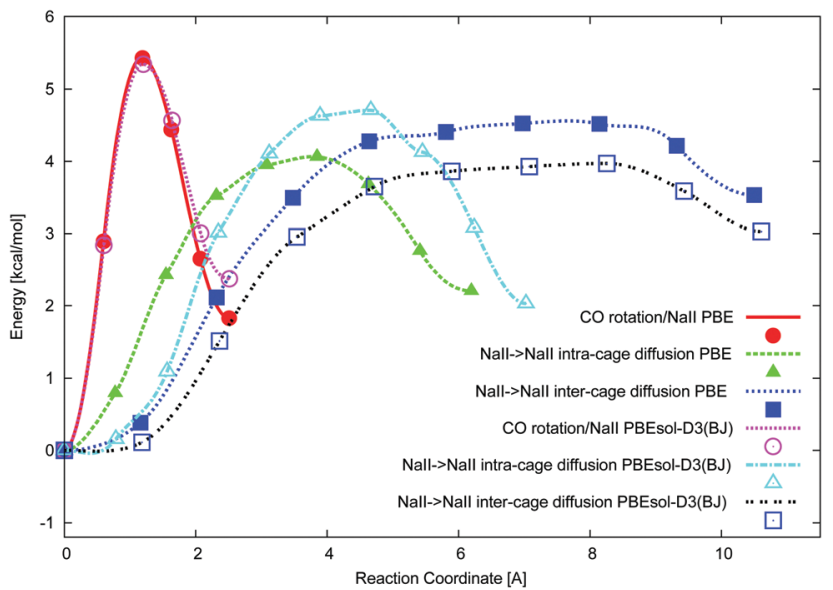

Fig. 4 Total energy ( $\mathrm{kcal} \mathrm{mol}^{-1}$ ) versus reaction coordinate (in $\AA$ ) for the $\mathrm{CO}$ rotation at the Nall site (circles), CO migration from one Nall to another $\mathrm{Na}^{\prime}$ ll site of the same supercage (triangles), and $\mathrm{CO}$ migration without rotation from the OC-Nall to $\mathrm{CO}-\mathrm{Nall}^{\prime}$ site of neighboring supercages via the $12 R$ window (squares) at the PBE (closed symbols) and PBEsol-D3(BJ) (open symbols) levels.

(Table 3). The verification of the calculated TS geometries for CO diffusion did not show a kind of "dual" intermediate, i.e., without imaginary frequencies, like the strong adsorption sites observed between alkali cations separated by around $7 \AA$ in other zeolites. ${ }^{21-23}$ The NaY structure leads to much larger NaII $\cdots \mathrm{Na}^{\prime}$ II distances $\sim 10 \AA$, which can be slightly shortened upon middle coverage due to the cation's deviation from the $6 \mathrm{R}$ plane (see the minor growth of $\left|\mathrm{Na}-\mathrm{O}_{z}\right|$ distances going from one to two CO molecules in Table 2). Na cations cannot move far from SII sites, for example, to stabilize hydrocarbonates in $\mathrm{NaY}$. The latter were found $\mathrm{d}^{52}$ and interpreted ${ }^{25}$ only for heavier cations which are less effectively bonded to the zeolite $\mathrm{O}_{\mathrm{z}}$ atoms in $\mathrm{KY}$ and CsY. Hence, we believe that dual $\mathrm{CO}$ sites are less probable for NaY.

Possibilities to change the $\mathrm{CO}$ orientation from NaII-CO to $\mathrm{Na}^{\prime} \mathrm{II}-\mathrm{OC}$ along the reaction coordinate (Fig. 1) or to maintain the NaII-CO orientation were therefore studied. Without $\mathrm{CO}$ rotation, the NaII-CO orientation steeply transforms to $\mathrm{Na}^{\prime} \mathrm{II}-\mathrm{OC}$, resulting in the lowest TSs $\left(4.1\right.$ and $4.7 \mathrm{kcal} \mathrm{mol}^{-1}$ at the PBE and PBEsol-D3(BJ) levels, respectively, in Table 3). The second route (with rotation) requires conserving the most energetically favorable NaII-CO geometry after the migration. It is conditioned by the possibility of $\mathrm{CO}$ rotation along the reaction coordinate (Fig. 1) and thus depends on the rotationtranslation interaction. Owing to the migration from the initial NaII site, the CO molecule moves far from the cation and hence will be influenced by a weaker electric field. It might decrease the $\mathrm{CO}$ rotational barrier along the NaII-Na'II trajectory. Then the molecule might rotate to maintain the energetically favored $\mathrm{Na}^{\prime} \mathrm{II}-\mathrm{CO}$ orientation after the jump. However, the barrier for the rotation-translation is similar to the barrier of rotation (5.3 instead of $5.4 \mathrm{kcal} \mathrm{mol}^{-1}$ at the PBE level in Table 3), a larger value versus the diffusion barrier. This does not demonstrate a decrease of the electric field gradient value along the trajectory between two NaII cations. It shows that the diffusion jump should be accompanied by a $\mathrm{CO}$ re-orientation $\dagger \dagger$ (from NaII-CO to Na'II-OC), avoiding CO rotation (Fig. 4).

The small energy difference per $\mathrm{CO}$ for either one or two $\mathrm{CO}$ molecules at one single site leads to a natural question, namely, can one CO molecule move to an already occupied NaII site? The PBE activation energy of such migration, $5.5 \mathrm{kcal} \mathrm{mol}^{-1}$, is slightly larger versus the activation energy of pure rotation, $5.4 \mathrm{kcal} \mathrm{mol}{ }^{-1}$, and hence it should also be less feasible compared to CO diffusion to a free NaII site with an activation energy of $4.1 \mathrm{kcal} \mathrm{mol}^{-1}$. The appearance of NaIII' leads to a much smaller barrier of 0.7 and $1.0 \mathrm{kcal} \mathrm{mol}^{-1}$ at the PBE and PBEsol-D3(BJ) levels, respectively, for the CO migration from NaII to NaIII (Table 3 and Fig. 4). Formally, considerably small barriers allow all possible site configurations producing very complex IR spectra in contrast to the experimental ones. We can thus consider neither NaIII nor NaIII' cations formed upon CO stimulation as part of a reliable NaY model.

In order to obtain a complete picture of the CO diffusion we also considered the inter-cage diffusion barrier. Passing the $12 R$ window between two NaII sites belonging to neighbor supercages leads to a minimal barrier of $4.5 \mathrm{kcal} \mathrm{mol}^{-1}$ (PBE) when the NaII-CO orientation at the starting point is changed to the NaII-OC orientation at the end point of the trajectory (an animation file of this migration is supplied in the ESI $\dagger$ ). The TS geometry corresponds to a CO position in the $12 R$ plane with the $\mathrm{C}$ atom separated by close NaII-C distances from both NaII atoms (5.128 and $5.975 \AA$ Å). Hence, the barriers increase along the series: intra-cage $\left(4.1 \mathrm{kcal} \mathrm{mol}{ }^{-1}\right)<$ inter-cage $\left(4.5 \mathrm{kcal} \mathrm{mol}^{-1}\right)<$ rotation plus translation in intra-cage $\left(5.3 \mathrm{kcal} \mathrm{mol}^{-1}\right)<\operatorname{rotation}\left(5.4 \mathrm{kcal} \mathrm{mol}^{-1}\right)$ at the PBE level.

\section{Discussion}

Grey et al. ${ }^{16,17}$ and Mellot-Draznieks et al. ${ }^{18}$ showed a possibility of $\mathrm{NaI}^{\prime}$ shift to the NaIII' site in the presence of adsorbed $\mathrm{C}_{2} \mathrm{~F}_{4} \mathrm{H}_{2}{ }^{16,17}$ or $\mathrm{CFCl}_{3}{ }^{18}$ species in the NaX type zeolite. Later this idea of $\mathrm{NaI}^{\prime}$ shift was discussed considering $\mathrm{CO}$ spectra in $\mathrm{NaY}$ and CuNaY. ${ }^{20}$ The close positions of the NaIII or NaIII' sites in $\mathrm{NaY}^{20}$ suggest similar results for the IR spectra and energies using either NaIII or NaIII' adsorption sites. The authors ${ }^{20}$ showed that the NaII-CO-NaIII' configuration $\left(\omega_{\mathrm{LF}}=-28 \mathrm{~cm}^{-1}\right)$ is only slightly less stable (by $0.8 \mathrm{kcal} \mathrm{mol}^{-1}$ ) than the NaII-CO-NaIII one $\left(\omega_{\mathrm{LF}}=-19 \mathrm{~cm}^{-1}\right)$ at the $\mathrm{B} 3 \mathrm{LYP} / 6-311++\mathrm{G}(\mathrm{d}, \mathrm{p})(\mathrm{Na}-\mathrm{CO}-\mathrm{Na}) /$ 6-31G(d)(Al, Si, $\mathrm{O}_{\mathrm{z}}, \mathrm{Na}^{\prime}$ ) level using a $42 \mathrm{~T}$ cluster model (Table 4 of ref. 20). The authors also considered a possible Na diffusion together with CO between close SIII and SIII' sites, ${ }^{20}$ although the problem of CO-stimulated diffusion of $\mathrm{NaI}^{\prime}$ to these sites was not resolved as it was experimentally shown for other adsorbates like $\mathrm{C}_{2} \mathrm{~F}_{4} \mathrm{H}_{2}{ }^{16,17}$ or $\mathrm{CFCl}_{3} .{ }^{18}$ Moreover, the experimental data for synthetic $\mathrm{Y}$ zeolites did not confirm the $\mathrm{CO}$ penetration into sodalite cages to interact with $\mathrm{NaI}^{\prime}$ and to stimulate its diffusion. ${ }^{10}$ Even if no evidence is known for such

$\dagger \dagger$ We use the word "re-orientation" instead of more frequent "isomerization" because it does not possess a chemical "flavor" which has no place in the current case. 
CO-induced diffusion in NaY at the moment, we considered its transformation to calculate the BS values of CO between NaIII and NaII cations and the respective diffusion coordinate. We did not analyze all possible positions of both NaIII and $\mathrm{NaIII}^{\prime 20}$ sites, limiting our calculations by considering only the NaIII case.

There are two possibilities to occupy the NaIII or NaIII' site: either to shift the cation from the most stable NaI or NaII site to the NaIII or NaIII' site (as in ref. 20 and herein), or to find a coverage for which the $\mathrm{CO}$ molecules start to stimulate a $\mathrm{NaI}^{\prime}$ transport without any loss of total stability of the system (which could be considered at the level of Gibbs potential or limited by enthalpy). An appropriate model should lead to stabilization of the system after $\mathrm{NaI}^{\prime}$ to NaIII diffusion and $\mathrm{CO}$ adsorption (or vice versa, CO adsorption and then Na diffusion) and not to the destabilization by 7.6, 6.1, and $5.8 \mathrm{kcal} \mathrm{mol}^{-1}$ at the PBE, PBEsol, and optB86d levels, respectively, as with the model herein without CO adsorption (see column 4 in Table S2 of the $\mathrm{ESI} \dagger$ ). The orders of the destabilization energy values are close to the decrease of the activation barrier of electric conductivity from $\mathrm{NaY}\left(17.7 \mathrm{kcal} \mathrm{mol}^{-1}\right)$ to $\mathrm{NaX}\left(12.5 \mathrm{kcal} \mathrm{mol}^{-1}\right)$ in dehydrated states. ${ }^{53}$ The conductivity is provided by Na jumps between allowed positions. The decrease of the energy barrier by $5.2 \mathrm{kcal} \mathrm{mol}^{-1}$ in $\mathrm{NaX}$ is the direct consequence of the presence of the less strongly coordinated NaIII cation in NaX. A compensation of the energy loss by a gain of CO specific adsorption energy (Section 3.2) is not sufficient in alkali forms. One should note that we occupied the NaIII site starting from the NaII cation of the same supercage (just by moving the NaII to the NaIII site and optimizing the fractional coordinates and cell parameters). It led to smaller destabilization of the zeolite as compared to the $\mathrm{NaI}^{\prime}$ to NaIII' drift because $\mathrm{NaI}^{\prime}$ is coordinated more strongly to the framework than NaII is.

The second way, i.e., $\mathrm{NaI}^{\prime}$ transport at higher $\mathrm{CO}$ coverage, requires totally different models. The main problem to apply this scheme with a $\mathrm{NaI}^{\prime}$ shift is the unknown coverage at which CO starts to stimulate the transport of $\mathrm{NaI}^{\prime}$ to the NaIII' sites. We did not consider this case as such a problem is outside the current study wherein we restrict ourselves to a domain of small NaY coverage.

Moreover, CO is an adsorbate molecule with a relatively weak electrostatic interaction which cannot stimulate any ionic transport of alkali and earth alkaline cations. $\neq$ t The heats of CO interaction with the Na cations (5.5-6.0 kcal mol ${ }^{-110-12}$ in NaX or even smaller $5.0 \mathrm{kcal} \mathrm{mol}^{-1}$ in $\mathrm{NaY}^{28}$ ) are smaller than those of $\mathrm{C}_{2} \mathrm{~F}_{4} \mathrm{H}_{2}\left(16.5 \mathrm{kcal} \mathrm{mol}^{-116,17}\right.$ ) or $\mathrm{CFCl}_{3}$ (around $8 \mathrm{kcal} \mathrm{mol}^{-1}$ for similar $\left.\mathrm{CF}_{2} \mathrm{Cl}_{2}{ }^{18}\right)$ molecules and hence the time-of-life of the respective $\mathrm{Na}-\mathrm{CO}$ complex to migrate ( $\mathrm{Na}$ and $\mathrm{CO}$ together) has to be shorter. Within a conventional range of adsorbates from $\mathrm{He}$ or $\mathrm{H}_{2}$ (no transport) to water (there is a cationic drift ${ }^{54-56}$ ), $\mathrm{CO}$ is closer to the $\mathrm{He}$ or $\mathrm{H}_{2}$ case.

An important part of our work is the demonstration of larger $\omega_{\mathrm{HF}}$ values in dicarbonyls relative to the ones for monocarbonyls, i.e., a $\Delta \omega_{\mathrm{HF}}$ value of $56.8 \mathrm{~cm}^{-1}$ for CO-NaII-CO compared to

\# Transition metal cations, whose chemical bonding with CO leads to stable carbonyl species, are not included in the discussion.
$44.1 \mathrm{~cm}^{-1}$ for NaII-CO at the PBE level (Table 2). $\S$ The coincidence of $\mathrm{CO}$ bands in mono- and dicarbonyls is usually admitted using cluster models. With the cluster approach, the estimation of $\mathrm{CO}$ perturbation in either OC-NaII-CO or CO-NaII-CO is hindered. We would like to emphasize that the $\Delta \omega_{\mathrm{HF}}$ variation is mainly the result of another CO position in dicarbonyls relative to within monocarbonyls and not the result of a CO-CO coupling (see Section 3.3). Formally, at the NaII site with approximate $C_{3}$ symmetry, one cannot find two identical symmetric positions for two CO molecules, $\uparrow$ imposing, morever, the condition of their optimal interaction (at least, minimal CO-CO repulsion, see non-equivalent positions of $\mathrm{CO}$ in the upper view of Fig. 2b). An additional difference in the non-equivalence of CO positions in dicarbonyls (not discussed in this work) can come from the various $\mathrm{Al}$ distributions in the $6 \mathrm{R}$ windows around each NaII site. ${ }^{57}$ The different CO positions for OC-NaII-CO (Fig. 2b) lead to different $\Delta \omega_{\mathrm{HF}}$ values irrespective of the strength of CO-CO coupling. As shown in Table 2, the $\omega_{\mathrm{HF}}$ value of $\mathrm{CO}$ in dicarbonyls can exceed the respective $\omega_{\mathrm{HF}}$ in monocarbonyls. As an explanation, it was mentioned that the minor contribution of the $\mu E$ dipole-field term to the heat of $\mathrm{CO}$ adsorption results from the small $\mathrm{CO}$ dipole $^{12}$ (see also all the energy components in Fig. 4 of ref. 58). Hence, a maximum electric field value at the optimal CO location cannot be a necessary requirement neither in mono- nor in dicarbonyls. The electric field $E$ can vary in any direction (decrease or increase) while going from mono- to dicarbonyls. As the main part of the COBS $(\mu(v=1)-\mu(v=0)) \times E$ depends mainly on the CO dipole change $\mu(v=1)-\mu(v=0)$ upon vibrational transition $0 \rightarrow 1$ and electric field $E$ (Table 4 of ref. 50), a simultaneous increase of $\omega_{\mathrm{HF}}$ is not forbidden due to a higher electric field in dicarbonyls.

The simple electrostatic picture of CO adsorption on alkali cationic sites allows some semi-quantitative estimation. Using results of previous empirical calculations, ${ }^{50,58}$ one can qualitatively evaluate the possible rotational barrier for adsorbed CO. An accurate electrostatic model for the NaCaA zeolite showed that the $\mathrm{CO}$ quadrupole-field gradient is the main contribution to the barrier of $\mathrm{CO}$ rotation along the line connecting $\mathrm{Ca}$ and the center of the $\alpha$-cage of $\mathrm{NaCaA}^{58}$ Regarding the higher Ca charge $(q(\mathrm{Ca})=1.2 e$ for model A of the NaCaA zeolite, see Table 4 of ref. 58) versus the one of $\mathrm{Na}$ in $\mathrm{NaY}$ (our estimation of Bader charge according to ref. 59 is $q(\mathrm{Na})=0.87 e$ ), the estimations for $\mathrm{NaCaA}$ can serve as upper boundaries for the CO location in NaY. The quadrupole-field gradient energy can be crudely evaluated to be $2.6 \mathrm{kcal} \mathrm{mol}^{-1}$ at the minimum of the total CO adsorption energy ( $R \sim 5.4$ a.u. in Fig. 4 of ref. 58). The barrier of a CO rotation by $90^{\circ}$ relative to the axis between the center

$\S \S$ Slightly larger $\Delta \omega$ values are also obtained for two CO molecules adsorbed at two different NaII cations at the PBE, PBEsol-D2, and optB86d levels. This also confirms the possible $\Delta \omega$ increases relative to the one for isolated monocarbonyls, even if the difference is smaller than for CO-NaII-CO using PBE.

ฯฯ Two nearly symmetric positions for two CO molecules could be found for the OC-NaIII-CO case due to the local $C_{2}$ symmetry, but we do not discuss the NaIII case as explained above. The symmetric OC-NaIII-CO location cannot be a favored one. 
of mass of $\mathrm{CO}$ and the Ca cation corresponds to the double value considering the opposite sign of the "quadrupole-field gradient" contribution after rotation. It is the consequence of the negative sign of the CO quadrupole moment. Hence, the barrier is around $5.2 \mathrm{kcal} \mathrm{mol}^{-1}$. The smaller contribution comes for the change in inductive (or polarization) energy $\Delta U_{\text {ind }} \sim \frac{1}{2} \times \alpha E^{2}$ upon CO rotation, with $\alpha$ being the CO polarizability and $E$, the electric field, i.e., $0.6 \mathrm{kcal} \mathrm{mol}^{-1}$ from Fig. 4 of ref. 58. The $U_{\text {ind }}$ variation after a CO rotation by $90^{\circ}$ can be obtained by re-scaling the ratio of the parallel (15.63 a.u. (ref. 30)) to perpendicular (11.97 a.u. (ref. 30)) polarizabilities which are the most important relative to the $E$ field at both orientations $0.63 \times(11.97 / 15.63)=0.5 \mathrm{kcal} \mathrm{mol}^{-1}$. This value is smaller than $U_{\text {ind }}$ calculated by Dempsey for $\mathrm{Ar} / \mathrm{NaY}$ $\left(0.9 \mathrm{kcal} \mathrm{mol}^{-160}\right)$ while the polarizability of $\mathrm{Ar}$, i.e., 11.04 a.u., ${ }^{3}$ is smaller than that of CO. ${ }^{61}$ In total, one gets $5.2+0.5=$ $5.7 \mathrm{kcal} \mathrm{mol}^{-1}$. The smaller rotational barriers of 5.4 and $5.3 \mathrm{kcal} \mathrm{mol}^{-1}$, calculated at the PBE and PBEsol-D3(BJ) levels, respectively (Table 3 ), show a qualitative coherence with the simple estimation above. The other electrostatic components (dipole-field etc.) of the energy terms are much smaller (see Fig. 4 of ref. 58). Despite the simple empirical scheme of pairwise potentials, Fig. 4 from ref. 58 shows a dominant role of the dispersion energy in the cationic zeolite A form. At the PBE0-D level, it was recently demonstrated for all siliceous zeolites that dispersion contributions vary between 70.1 and $94.3 \%$ of the total energies. ${ }^{62}$

\section{Conclusions}

The NaY zeolite remains a perspective material for separation of gas mixtures. In this work, we tested three selected DFT functionals using PBC and we have found the better agreement with experimental heats of CO adsorption at the PBE and PBEsol levels than with optB86d and PBEsol-D2. In contrast, the difference in the $\mathrm{CO}$ energies at the NaII-CO to NaII-OC orientations calculated at the optB86d level is closer to the experimental difference. We obtained smaller activation energy for CO diffusion in the intracrystalline porous space between neighboring NaII sites of one FAU supercage as compared to CO rotation at one NaII center. The presence of nearly symmetric sub-bands was considered as an argument in favor of the $\mathrm{CO}$ rotation. Herein, the fine structure of the vibrational $\mathrm{C}-\mathrm{O}$ bands is explained by the different $\mathrm{CO}$ locations of adsorbed mono- and dicarbonyl species instead of CO rotation. This result agrees with the absence of rotational branches in the IR spectra due to hindered CO rotation in other zeolites. The order of the rotational barrier values agrees with the main interaction energy contribution between the electric field gradient and the CO quadrupole in NaCaA obtained in the literature. This barrier is smaller for the NaII-CO to Na'II-OC type jump (changing the $\mathrm{CO}$ orientation without rotation) than for the NaII-CO to $\mathrm{Na}^{\prime} \mathrm{II}-\mathrm{CO}$ route (conserving the $\mathrm{CO}$ orientation due to rotation). The CO jump without rotation explains the redistribution of the high frequency (NaII-CO) and low frequency (NaII-OC) intensities with temperature. This illustrates that the electrostatic field gradient does not decrease too steeply from the cation to the center of the zeolite $\mathrm{Y}$ cage to allow $\mathrm{CO}$ rotation even for monovalent cations. Therefore, such CO behavior in NaY may be extended for divalent zeolite forms with higher field gradients. We did not obtain any confirmation of $\mathrm{NaIII}$ formation in $\mathrm{NaY}$ with smaller activation energies of both diffusion and rotation regarding the $\mathrm{CO} / \mathrm{NaY}$ spectra. Hence, the barriers for $\mathrm{CO}$ motions in $\mathrm{NaY}$ at the PBE level increase as follows: intra-cage diffusion $<$ inter-cage diffusion $<$ rotation. This shows that CO desorption is more probable than its rotation in NaY. Such results can be useful for accurate modeling of restricted $\mathrm{CO}$ dynamics in catalyzed reaction systems or adsorption over zeolites as well as in microporous systems in general.

\section{Acknowledgements}

The authors thank the Supercomputing Center of Lomonosov Moscow State University ${ }^{63}$ for computational time. This research used the resources of the "Plateforme Technologique de Calcul Intensif (PTCI)" (http://www.ptci.unamur.be) located at the University of Namur, Belgium, which is supported by the F. R. S.-FNRS under convention no. 2.4520.11. The PTCI is a member of the “Consortium des Équipements de Calcul Intensif (CÉCI)” (http:// www.ceci-hpc.be). AAR and AVL thank RFFI for Grant 17-53-18026.

\section{References}

1 M. Kanezashi, J. O'Brien-Abraham, Y. S. Lin and K. Suzuki, AIChE J., 2008, 54, 1478-1486.

2 M. Kanezashi and Y. S. Lin, J. Phys. Chem. C, 2009, 113, 3767-3774.

3 J. A. Delgado, V. I. Águeda, M. A. Uguina, J. L. Sotelo, P. Brea and C. A. Grande, Ind. Eng. Chem. Res., 2014, 53, 15414-15426.

4 J. Xiao and J. Wei, Chem. Eng. Sci., 1992, 47, 1123-1141.

5 F. Jousse, S. M. Auerbach and D. P. Vercauteren, J. Phys. Chem. B, 1998, 102, 6507-6514.

6 S. M. Auerbach, Int. Rev. Phys. Chem., 2000, 19, 155-198.

7 A. A. Rybakov, A. V. Larin, G. M. Zhidomirov, D. N. Trubnikov and D. P. Vercauteren, Comput. Theor. Chem., 2011, 964, 108-115.

8 A. A. Rybakov, I. A. Bryukhanov, A. V. Larin and G. M. Zhidomirov, Int. J. Quantum Chem., 2015, 115, 1709-1717.

9 A. A. Rybakov, I. A. Bryukhanov, A. V. Larin and G. M. Zhidomirov, Pet. Chem., 2016, 56, 259-266.

10 T. A. Egerton and F. S. Stone, Trans. Faraday Soc., 1970, 66, 2364-2377.

11 T. A. Egerton and F. S. Stone, J. Colloid Interface Sci., 1972, 38, 195-204.

12 T. A. Egerton and F. S. Stone, J. Chem. Soc., Faraday Trans. 1, 1973, 69, 22-38.

13 C. Otero Areán, G. T. Palomino, A. A. Tsyganenko and E. Garrone, Int. J. Mol. Sci., 2002, 3, 764-776.

14 K. Hadjiivanov, H. Knözinger, E. Ivanova and L. Dimitrov, Phys. Chem. Chem. Phys., 2001, 3, 2531-2536. 
15 A. A. Tsyganenko, P. Y. Storozhev and C. Otero Areán, Kinet. Catal., 2004, 45, 530-540.

16 C. P. Grey, F. I. Poshni, A. F. Gualtieri, P. Norby, J. C. Hanson and D. R. Corbin, J. Am. Chem. Soc., 1997, 119, 1981-1989.

17 K. H. Lim and C. P. Grey, J. Am. Chem. Soc., 2000, 122, 9768-9780.

18 C. Mellot-Draznieks, J. Rodriguez-Carvajal, D. E. Cox and A. K. Cheetham, Phys. Chem. Chem. Phys., 2003, 5, 1882-1887.

19 D. F. Plant, G. Maurin, H. Jobic and P. L. Llewellyn, J. Phys. Chem. B, 2006, 110, 14372-14378.

20 Z. Nour, H. Petitjean and D. Berthomieu, J. Phys. Chem. C, 2010, 114, 17802-17811.

21 C. Otero Areán, M. Rodríguez Delgado, K. Frolich, R. Bulánek, A. Pulido, G. Fiol Bibiloni and P. Nachtigall, J. Phys. Chem. C, 2008, 112, 4658-4666.

22 E. Garrone, R. Bulánek, K. Frolich, C. Otero Areán, M. Rodríguez Delgado, G. Turnes Palomino, D. Nachtigallová and P. Nachtigall, J. Phys. Chem. B, 2006, 110, 22542-22550.

23 O. V. Manoilova, M. Peñarroya Mentruit, G. Turnes Palomino, A. A. Tsyganenko and C. Otero Areán, Vib. Spectrosc., 2001, 26, 107-111.

24 A. V. Larin, Microporous Mesoporous Mater., 2014, 200, 35-45. 25 A. V. Larin, Microporous Mesoporous Mater., 2016, 228, 182-195.

26 C. Otero Areán, A. A. Tsyganenko, E. Escalona Platero, E. Garrone and A. Zecchina, Angew. Chem., Int. Ed., 1998, 37, 3161-3163.

27 P. J. Fenelon and H. E. Rubalcava, J. Chem. Phys., 1969, 51, 961-967.

28 E. A. Paukshtis, R. I. Soltanov and E. N. Yurchenko, React. Kinet. Catal. Lett., 1981, 16, 93-96.

29 H. Förster, W. Frede and M. Schuldt, J. Mol. Struct., 1982, 80, 195-198.

30 A. A. Tsyganenko, E. Escalona Platero, C. Otero Areán, E. Garrone and A. Zecchina, Catal. Lett., 1999, 61, 187-192.

31 T. A. Wesołowski, A. Goursot and J. Weber, J. Chem. Phys., 2001, 115, 4791-4797.

32 G. Kresse and J. Hafner, Phys. Rev. B: Condens. Matter Mater. Phys., 1993, 47, 558-561.

33 G. Kresse and J. Furthmüller, Phys. Rev. B: Condens. Matter Mater. Phys., 1996, 54, 11169-11186.

34 L. Benco, T. Bucko, J. Hafner and H. Toulhoat, J. Phys. Chem. B, 2004, 108, 13656-13666.

35 F. Göltl and J. Hafner, J. Chem. Phys., 2012, 136, 64501.

36 J. P. Perdew, K. Burke and M. Ernzerhof, Phys. Rev. Lett., 1996, 77, 3865-3868.

37 J. P. Perdew, A. Ruzsinszky, G. I. Csonka, O. A. Vydrov, G. E. Scuseria, L. A. Constantin, X. Zhou and K. Burke, Phys. Rev. Lett., 2008, 100, 136406.

38 P. E. Blöchl, Phys. Rev. B: Condens. Matter Mater. Phys., 1994, 50, 17953-17979.
39 G. Kresse and D. Joubert, Phys. Rev. B: Condens. Matter Mater. Phys., 1999, 59, 1758-1775.

40 S. Grimme, J. Comput. Chem., 2006, 27, 1787-1799.

41 S. Grimme, J. Antony, S. Ehrlich and H. Krieg, J. Chem. Phys., 2010, 132, 154104.

42 S. Grimme, S. Ehrlich and L. Goerigk, J. Comput. Chem., 2011, 32, 1456-1465.

43 G. Henkelman, B. P. Uberuaga and H. Jónsson, J. Chem. Phys., 2000, 113, 9901-9904.

44 D. Sheppard, R. Terrell and G. Henkelman, J. Chem. Phys., 2008, 128, 134106.

45 P. Ugliengo, D. Viterbo and G. Chiari, Z. Kristallogr. - Cryst. Mater., 1993, 207, 9-23.

46 B. M. Bode and M. S. Gordon, J. Mol. Graphics Modell., 1998, 16, 133-138.

47 N. E. Ghermani, C. Lecomte and Y. Dusausoy, Phys. Rev. B: Condens. Matter Mater. Phys., 1996, 53, 5231-5239.

48 I. A. Bryukhanov, A. A. Rybakov, V. L. Kovalev, A. V. Larin and G. M. Zhidomirov, Dalton Trans., 2015, 44, 2703-2711.

49 D. Saha and S. Deng, J. Chem. Eng. Data, 2009, 54, 2245-2250.

50 A. V. Larin, D. P. Vercauteren, C. Lamberti, S. Bordiga and A. Zecchina, Phys. Chem. Chem. Phys., 2002, 4, 2424-2433.

51 K. Hadjiivanov and H. Knözinger, Chem. Phys. Lett., 1999, 303, 513-520.

52 G. D. Pirngruber, P. Raybaud, Y. Belmabkhout, J. Čejka and A. Zukal, Phys. Chem. Chem. Phys., 2010, 12, 13534-13546.

53 F. J. Jansen and R. A. Schoonheydt, J. Chem. Soc., Faraday Trans. 1, 1973, 69, 1338-1355.

54 T. I. Barry and L. A. Lay, J. Phys. Chem. Solids, 1966, 27, 1821-1831.

55 T. I. Barry and L. A. Lay, J. Phys. Chem. Solids, 1968, 29, 1395-1405.

56 M. Jeffroy, E. Borissenko, A. Boutin, A. Di Lella, F. Porcher, M. Souhassou, C. Lecomte and A. H. Fuchs, Microporous Mesoporous Mater., 2011, 138, 45-50.

57 S. Huber and H. Knözinger, Appl. Catal. A, 1999, 181, 239-244.

58 A. V. Larin, L. Leherte and D. P. Vercauteren, Phys. Chem. Chem. Phys., 2002, 4, 2416-2423.

59 W. Tang, E. Sanville and G. Henkelman, J. Phys.: Condens. Matter, 2009, 21, 84204.

60 E. Dempsey, Proc. Conf. Molecular Sieves 1967, London: Society of Chemical Industry, London, 1968, pp. 293-305.

61 H. B. Levine and G. Birnbaum, J. Chem. Phys., 1971, 55, 2914-2917.

62 E. I. Román-Román and C. M. Zicovich-Wilson, Chem. Phys. Lett., 2015, 619, 109-114.

63 V. Sadovnichy, A. Tikhonravov, V. Voevodin and V. Opanasenko, in Contemporary High Performance Computing From Petascale toward Exascale, ed. J. S. Vetter, CRC Press, Boca Raton, USA, 2013, pp. 283-307. 